\title{
Intangible Assets are More Valuable than the Tangible Study on the Innovation and Development of the Traditional Time-Honored Brands
}

\author{
Jia Li \\ College of Art,Southwest Minzu University,Chengdu,610041,Sichuan,China \\ 80723312@qq.com
}

Keywords: Tangible; Intangible; Time-honored brand; Brand heritage; Brand innovation

\begin{abstract}
Chinese society is a natural economy that is self-sufficient. It is a society based on farming. Except for planting land, it is the development of handicrafts. Therefore, the most demanding quality instead of the brand, as the product itself is material, and the brand is spiritual. It is intangible. There is a difference between branded and non-branded things. The traditional "time-honored brand" has a distinctive traditional cultural background and profound cultural heritage. It refers to a national brand with a long history and a good reputation, and has the skills and services inherited from generation to generation. This article aims to explore the intangible value and brand value of time-honored commodities. With the continuous development of globalization and integration of the world economy, China is faced with economic restructuring from a manufacturing nation to a branding superpower, China's time-honored products shoulder a major historical mission.
\end{abstract}

\section{Tangible Material and Intangible Spirit}

The great thinker and philosopher Laozi in the ancient Chinese period of the Spring and Autumn Period said: "Dao produce one, one produce two, two produce three and three produce all things ----". Tao is the objective law, which is the law of nature. According to Chapter 40, morality, "Repetion is the actions of the Dao, weakness are used by the Dao, and the Tao of the weak is used. All things in the world are born and there are born." It means that the cyclical movements are the movement of the Dao, and the role of the Dao. It is subtle, that all things in the world are produced by tangible physical objects, and that physical objects are produced by intangible substances. All things in life follow the laws of nature, and the laws of nature are manifested in two levels: The first is the tangible law, that is, the law of cause and effect. The law is tangible, visible, and can be copied. The second is the intangible spiritual order. It cannot be seen and cannot be copied and compared. The laws and spirits in the universe are a kind of interaction and mutual transformation. In the laws of nature, they are intangible and tangible. The intangible value is far greater than the value of tangible. What does this mean? For example, a luxury bag, its value is not large, the material may be ordinary leather, the function is to store things or property, its true value lies in which master made it, what kind of brand, and the culture behind the brand. However, the brand is intangible and is the controlling hand behind the product, so the price of the bag is far exceeds its material and cost. Similarly, a pair of curio walnuts or an ancient chinaware will also be seen as a collection.[1] There are no practical functions on them, but their cultural concepts and implication are immeasurable. These are intangible spiritual energies which make if possible for the existence of life, and the existence value of the material.

So what kind of tangible products does China create? Dr. Joseph Needham, a renowned scientist in the United Kingdom, began studying China's science and culture in the 1930s. In his masterpiece "The History of Science and Technology in China", he combed China's inventions and creations to make the world understand China's History of science ideology, professional history of various disciplines. Joseph Needham thinks that China has a strong foundation of humanities and technology. And the ancient scientific and technological inventions are ahead of the world, such as the four great inventions of ancient China - the invention of movable type printing, the compass, 
papermaking and the gunpowder, our oldest chronograph - the determination of pot leaks, geodetic surveying - the determination of the meridian, as well as the appearance of waterwheels, weaving machines and ceramic bronze wares, the Chinese people who used science and technology to make inventions accounted for 54 percent of the world. From the pre-Qin period to the Ming and Qing dynasties, apart from the four great inventions, there are still a lot of creating results of the mathematics and traditional science fields, but these are mostly personal experience or accumulation, there is no systematic theory of logic, because they did not get the government's attention and failed to bear fruit, so many inventions and creations are not applied in real life. After we experienced the rapid decline of the Chinese society in the late Kangxi era, we were transformed from the world's greatest to the world's oldest, from a great nation with creativity to a country that has accumulated poverty for more than 200 years.[2]

Joseph Needham's research is based on later European contributions. The essence is to look back on the contributions of the Chinese in the past. His works not only help the Chinese rebuild scientific confidence, but also overcome the pride and arrogance of Europeans. Tell the world that science has a deep and profound foundation in Chinese civilization. Since ancient times, Chinese civilization has focused on practical, tangible things and weak in abstract, logical, and analytical scientific systems. This is precisely the unique characteristics and social forms of Chinese society.

\section{Intangible Brand, is the Creation of Spiritual Values}

Since ancient times, Chinese society has always been characterized by farming and natural economy. The natural economy based on farming requires the development of handicraft in addition to planting. Handicrafts are self-sufficient everyday items such as hand-made clothing. The hard-working people focus on the material and quality of products only, With the development of handicraft industry, it is inevitable that there will be higher requirements for handicrafts. Crafts are not only the requirements of materials, but also the pursuit of spiritual life.

Historical records that since the beginning of the Ming Dynasty in China, there has been plenty in the regions of south Yangzi River, and there have been many Chinese handicrafts with brand values. People who like to collect know that for example, people like jade must know Luzi Gang's jade, there are Shi Dabin's dark-red enameled pottery, Jiang Qianli's screw uranium lacquerware, Zhang Mingxi's hand stove, Zhou Bao's treasure inlay, Zhu Song's bamboo carvings, etc. Eighty percent of these arts and crafts that can name people are people of the late Ming period. What is the person's name? It was the brand at the time! For example, we know that Ford, Mercedes-Benz cars, Boeing aircraft, these are names, Western products are based on personal names, who is responsible, it's the name. So we are only used to Western brands, but are not used to the value of that name in Western brands, so there is no brand awareness. Then the Chinese nation's brands have been cut from the Qing Dynasty by a single knife, instead by the Qing Dynasty Emperor Kangxi's system, and today it is made in China. Before the reform and opening up, we ignored the brand and completely lost the brand and the intangible value and culture.

After the reform and opening up, China's first brand was Li Ning, a capitalized English letter. It began with a sense of branding. This is a very important awareness. A trademark is an intangible asset. We had such a strong sense of branding in the late Ming dynasty. At that time, commerce was also very developed. However, we did not seize this opportunity, The United Kingdom which is far away from China quickly completed its first industrial revolution in the 16th century. The first patent law was promulgated. This law stipulates that inventions and creations cannot be plagiarized, which signifies the final formation of the British patent system, that is, this law makes Britain a empire on which the sun never set..

The brand's assets are mainly reflected in the brand's core value, or brand core value is also the essence of the brand. The value of a brand as an intangible asset lies not only in the history and development of the brand, but also in the fact that it becomes an emotional value that allows consumers to receive sought after purchases. The brand represents credibility, quality, and service. So in nowadays, the brand has become an important cultural symbol. Its brand depends on a certain way of life or a concept. The target of sales is not only a product but an image. This image value is 
condensed in the brand, so it is the reason why the brand is more valuable than the product.

\section{The Heritage of the Old Chinese Brand}

From the history of China, it is illustrated that there was no lack of Chinese creation since the middle and late period of the Ming Dynasty. the essence is the inheritance and development of Chinese national culture. These amazing rich cultural heritages are integrated into the spiritual blood of the Chinese nation, accumulating and moistening the contemporary people and Future generations. The independent brands of China's industry and commerce represent the essence and quality of our country's traditional business culture. It is a symbol of China's manufacturing quality and reputation. It witnessed the development characteristics and inheritance of Chinese commercial civilization, and is indeed a treasure of traditional Chinese culture.[3]

The time-honored brand refers to a product with a long history, which has been passed down from generation to generation. It has a distinct traditional Chinese cultural background and profound cultural heritage. It is the best product in the competition of commercial and handicraft industries for hundreds of years. A time-honored brand is a gold brand with hundreds of years of arduous pioneering, painstaking efforts, glorious history, shaping a well-known glorious image of China and foreign countries. For example, Quanjude Roast Duck has become a symbol of Beijing, Donglaishun mutton, China's first Neiliansheng which made cloth shoes, delicious pickles named Liubiju, these famous time-honored products inherit the soul of Chinese culture in the accumulation of history, with distinctive Chinese traditional culture Backgrounds are all unique to China. Over the years, the overall operating status of China's time-honored brands has not been very good. In the 1960s, because of the public and private partnerships, many old brands were merged, the Cultural Revolution of the 1970s, the production and management of old brands were undermined, and the market economy in the 1990's has been advanced in the West. [4]The business philosophy and the impact of a variety of formats have collapsed. With the accelerating trend of economic globalization, the living environment of China's time-honored products is constantly threatened. Many have been mottled and fragile, and it is so important to inherit and protect well-established brands. There are many reasons for the decline of the time-honored brand, but the key is the company's own awareness of intellectual property protection is weak, the brand does not register more counterfeit trademarks, lack of competitiveness can not respond to the fierce market. How to shape the brand? How to inherit and develop to adapt to domestic and foreign markets? The time-honored companies must continue to innovate and capture the market with high-quality and high-efficiency products. As more and more high-quality products are in the market today, Chinese time-honored companies must clearly understand that competition among enterprises is the competition of brands. Brands can not be copied and imitated, product brands are different, corporate culture is different, business philosophy is different, the sales price is different, behind this price gap is the support of intangible assets. The spiritual value of the brand is intangible. It must pay attention to the brand's innovation and construction, use the brand to create wealth, and win in the market competition.

Innovation is the soul of a nation's progress and an inexhaustible motive force for the country's prosperity. Innovation comes from the development of people's wisdom, the liberation of the soul, the pursuit of aspirations, all of which must be based on certain social and political conditions. Innovation is encouraged and the rights of creators are guaranteed. Today's Chinese government has begun to attach importance to inherit our traditional culture. With the ever-expanding foreign exchanges, China's traditional products will emerge from the perspective of all countries in the world.

\section{0-Year-Old Brand Value Innovation and Development}

Brand value innovation means that, within a certain range of costs, on the basis of continuous improvement of products and services, new brand values are used to satisfy customers' pursuit of higher value objectives of the original products or services. Through the brand's new business strategy, the company realizes the management and maintenance of brand value and achieves the 
purpose of brand value creation and value enhancement. The products, techniques or services inherited by the time-honored brands, as well as brands with good reputation and considerable value, must be properly utilized to focus on the continuous and innovative development of product brands. Brand innovation is a continuous process.[5] It runs through all phases of the product brand life cycle. If a hundred-year brand enterprise does not possess the spirit of innovation and does not understand that the product must be constantly updated according to market demand, then the company's product is even a famous brand products, but also can not withstand the merciless elimination of market competition mechanism, the company will eventually be eliminated by fierce competition. Innovation is also the core of enterprise competition and a key factor in the survival and development of the company. Innovation is a challenging work. It is necessary to break through the old ways of thinking and production methods, learn from failures without failing in failure, encourage employees to establish a strong spirit of innovation, and explore new knowledge, promote the scientific and technological innovations and management innovations based on learning from previous generations to create outstanding achievements in civilization. and develop their own technological products on the basis of the inheritance of their ethnic products to surpass the world's advanced powers.[6]

Since the 20th century, the science and technology tendency of enterprise has been pursuing the goal of advanced production equipment, specialized technicians, and standardized business management. The reform of the enterprise management system is a profound reform with a revolutionary significance. The pursuit of scientific and technological progress is an important driving force for the development of enterprises. The scientific and technological development of enterprises has positive significance for the competition, Under the background of new economic globalization and further open markets, traditional time-honored brands are enterprises that directly participate in the international market. Their development advantages should be concentrated on the cultural characteristics of time-honored brands. Therefore, to revitalize the development of time-honored brands, we must effectively give full play to the historical and cultural advantages of time-honored brands, protect the core skills and cultural heritage of old-established enterprises, increase the intensity of publicity and promotion, promote the integration of Chinese and foreign cultures, and expand the overseas reputation of time-honored brands. At the same time, promote the innovation of cultural expression of the time-honored brand, guide the time-honored companies to align themselves with the modern market economic system, expand their own business activities in the competition, and shape the traditional new image of the time-honored brand.

\section{Acknowledgements}

Fundamental Research Funds for Central Universities, Young Teachers Fund Project, Research on the Product Design Status and Development of China's "Time honored Brand" ,Item Number:2017SZYQN02

\section{References}

[1] X.Wang.:The Inheritance and Change of Chinese Time-honored Brands (Intellectual Property Publishing House, China 2015),p.25

[2] J.J.Zhang,W.H.Liu:The case of a Time-honored company and its development report (China Market Press, China 2015),p.189

[3] Q.Yan,H.Yan:Culture Research Association. Inheritance and Innovation(Jinan University Press, China 2013),p.12

[4] C.R.Wang,C.Li and Y.J.Wang:The value of the Time-honored Brands(China Economic Publishing House, China 2012),p.35

[5] S.Y.Tong:The History of Chinese Handicraft Business Development(Zhonghua Book Company, China 2005),p.90

[6] L.R.Kong,D.Z.Li: China's Time-honored Brands (Higher Education Press, China 1998),p178 